\title{
As antigüidades da Gallaecia na obra historiográfica de Afonso X
}

\author{
Helena de Carlos Villamarín \\ Universidade de Santiago de Compostela
}

DOI: 10.17075/gtax.2021.009 



\section{INTRODUCIÓN}

$\mathrm{O}$ xeito en que os historiadores, como representantes ou cando menos cronistas das sociedades, configuran o seu pasado máis remoto é revelador das expectativas deses mesmos tecidos sociais, sexan estes agrupados como pobos, nacións, castas, familias ou dinastías. Hai agora case trinta anos que defendín a miña tese de doutoramento, un traballo de mocidade que rematou por ter forma de libro uns anos máis tarde ${ }^{1}$, mentres outros investigadores, paralelamente, se facían preguntas moi semellantes á que eu formulara como punto de partida² ${ }^{2}$ Como é obvio e propio de toda investigación rigorosa, eu mesma e, así, os outros estudosos que canda min se adentraron nos territorios do imaxinario colectivo primixenio servímonos de traballos previos dedicados a estas cuestións. Mais teño a sensación de que o tema se fixo aínda máis recorrente como motivo de investigación, tanto no referente á historiografía antiga, como á medieval, como mesmo á moderna e contemporánea, nos últimos vinte anos. Pode ser este un efecto expansivo e colateral da obra fundacional de Benedict Anderson ${ }^{3}$ ou propio dunha época obsesionada polas identidades colectivas. É tamén normal que, como investigadores dun pasado remoto, nos vexamos atraídos polo xeito en que os colectivos dese pasado imaxinaron a raíz da que derivaron, como foron os tempos fundacionais, baixo quen os viviron, quen marcou, en certo modo, os seus riscos definitorios. En definitiva, como quixeron presentarse perante outros grupos sociais.

É o meu propósito nas páxinas que seguen analizar e intentar entender a configuración que Afonso X fai da protohistoria da «Galizia» nas súas obras de historia, a Estoria de Espanna e a General Estoria, dous proxectos xerados en parte en paralelo, confeccionados emporiso en momentos distintos do tempo e pensados tamén con distintos propósitos, aínda que estes se poidan entender dun xeito

1 Dirixida polo profesor José Manuel Díaz de Bustamante, defendida co título de Las Antigüedades de España. Fundadores y reyes míticos en la literatura medieval o 16 de decembro de 1992. Foi logo publicada como libro, con algúns cambios, na prestixiosa colección do Centro Italiano di Studi sull’Alto Medioevo. Cf. De Carlos Villamarín (1996).

2 Precedente para min lamentablemente descoñecido, contemporáneo do meu traballo cando este tiña aínda só forma de tese, foi a obra de referencia sobre materia afonsina de Fernández Ordóñez (1992). Algúns dos temas abordados por min, e que son de grande interese para esta contribución, foran antes tratados por Estévez Sola (1990) e en paralelo ao meu traballo por González García (1997 e 1998).

3 Refírome evidentemente á xa clásica Imagined Communities: Reflections on the Origin and Spread of Nationalism, publicada por vez primeira en 1983 e traducida ao español en 1993. 
máis complementario que oposto (Catalán 1962, Rico 1984, Fernández Ordóñez 1992, Rodríguez Porto 2017). Por protohistoria entendo a anterior á romanización, ou cando menos ao relato xa organizado da presenza romana na Península, que no caso afonsino posúe un claro punto de inflexión coa entrada de Hispania na historia de Roma con motivo das guerras púnicas. Evidentemente, o que Afonso X dedique a esta zona da Península está en relación co relato establecido arredor do resto de Hispania. Sen caer na decepción que manifesta Ramón Lorenzo (1999) ao estudar as mencións a Galicia do Rei Sabio, é xusto tamén deixar claro desde un primeiro momento que non imos atopar neste caso un relato especialmente prolixo sobre a historia remota do noso país.

\section{PEGADAS DOS AUTORES TARDOANTIGOS}

A visión do que poderiamos denominar as «Antigüidades da Gallaecia» ${ }^{4}$ que se percibe na Estoria de Espanna de Afonso X emana en boa medida do seu modelo máis claro nestes aspectos, que é a Historia de rebus Hispaniae ou Historia Gothica de Rodrigo Ximénez de Rada (ca. 1246), pero ao tempo incorpora elementos que nos fan percibir o resultado como xa afastado desa fonte e, xa que logo, da tradición isidoriana. Non podemos esquecer que Isidoro de Sevilla, especialmente nas Etimoloxías ou Origines, se fai eco de noticias extractadas de Xustino, un autor do século III da nosa era que dedica aos Gallaeci unha parte proporcionalmente significativa do libro 44 das súas historias, pola súa vez epítome da obra de Pompeio Trogo (s. I), consagrado ao pasado prerromano da Península Ibérica, ou, para sermos máis precisos, de Hispania. Para sintetizar os elementos que configuran esa imaxe da Hispania primitiva dada por Xustino: a descrición laudatoria de Hispania e das súas xentes, cunha mención especial a Viriato $(44,1$ e 2); a riqueza en cabalos da Lusitania e da Gallaecia, que leva a falar da lenda de Teucro e as súas fundacións, entre as que se conta o soar dos galegos cuxa riqueza mineral comenta laudatoriamente (44, 3); Tartessos e os seus reis Gárgoris e Habis (44, 4, 1-14); Xerión, rei doutra parte de Hispania, cuxa riqueza en gandos atrae a Hércules (44, 4, 15-16); os cartaxineses como primeiros ocupantes pola forza «post regna deinde Hispaniae», as guerras púnicas, e a final pacificación e incorporación ao imperio de Roma por Augusto $(44,5)$. Este é un rico e completo esquema, no que podemos atopar un fío temático dun punto ao outro: de Viriato enlazamos coa Lusitania e dela coa Gallaecia, cuxas orixes se comentan. Ao falar da riqueza do seu terreo, pásase a tratar dos primeiros reis doutros lugares de Hispania, o cal conduce a Xerión e ao personaxe de Hércules. Desta deidade cóntase que foi venerada polos fenicios e que eles a trouxeron a Gades, que propicia a entrada dos cartaxineses en Hispania e a participación desta nas guerras púnicas. Pero dese

4 Sobre o concepto de Antiquitates, cf. De Carlos Villamarín (1996: 23-56). 
esquema só sobrevivirá no mundo medieval a laudatio Hispanie, da que non vou tratar aquí, e a figura de Xerión, polo que respecta ao pasado mítico.

Por resumir moito, un eco xa afastado destas noticias chega a Ximénez de Rada, e unha onda aínda máis feble deste esquema plásmase na Estoria de Espanna de Afonso X. Isto é perceptible na noticia que máis claramente se refire aos Gallaeci das transmitidas por Xustino, a do nóstos ou viaxe de regreso de Teucro desde a guerra de Troia ata o soar dos Gallaeci, dos que se presenta como fundador 5 . Esta noticia é aínda recollida por Isidoro de Sevilla nas súas Etimoloxías (9, 2, 104), pero xa non por Ximénez de Rada, quen vincula a orixe dos galegos aos gálatas compañeiros de Hércules (De rebus Hispaniae 1, 4, 29-35). Tampouco aparece na Estoria de Espanna afonsina, fiel aquí ao Toledano (Primera Crónica General 3: Menéndez Pidal 1906: 6): «e los otros que llamaron galacios poblaron Galizia, que antiguamientre solie seer desdell agua de Cea fastal puerto de Gaya [...] e poblaron una grand partida de Galizia que era yerma entre los dos rios que llaman Duero e Minno, e pusieron le nombre Portogal»; (Primera Crónica General 7: Menéndez Pidal 1906: 10): «E una gran partida de la gente que el (Hércules) traye fueron de Galacia, e mandolos poblar alii e por esso fue llamada aquella tierra Galizia». Omisión curiosa, se é que de omisión voluntaria se pode falar, cousa que creo que é posible. Non o sería tanto no caso de Ximénez de Rada. Que o bispo toledano non manexe a riquísima e case única información que sobre o pasado prerromano da Península, e por conseguinte da Gallaecia, proporciona o abreviador de Pompeio Trogo paréceme debido non á vontade de non facelo, senón talvez á imposibilidade de facelo. E iso porque é bastante probable que Ximénez de Rada non coñecese o texto de Xustino ${ }^{6}$. Malia que menciona entre as súas fontes a Pompeio Trogo, precisamente a cita dun autor cuxo texto está perdido e só é coñecido pola abreviación composta por Xustino, pode dar unha pista sobre o carácter secundario desta mención. Ximénez de Rada nomea entre as auctoritates utilizadas por el a Pompeio Trogo porque a súa nómina de autoridades é indirecta, é dicir, está tomada da súa fonte, un autor do século vi, Xordanes, quen menciona a Pompeio Trogo nos seus Getica 6, 48. Nesa mesma nómina Ximénez de Rada cualifica a Pompeio Trogo de «historiarum orientalium sollicitus supputator», algo así

5 Propiamente, o de Teucro non é un nóstos, xa que este concepto implica a idea de regreso ao lugar de partida, algo aplicable ao exemplo máis coñecido literariamente, o de Odiseo ou Ulises, que viaxa durante dez anos para regresar á súa Ítaca. O caso de Teucro en relación coa Gallaecia sería máis análogo ao de Eneas en relación co lugar onde máis tarde se edificará Roma: ningún dos dous heroes procede do sitio en que remata por asentarse, senón que ese establecemento obedece ao designio divino ou á casualidade. Con todo, a diferenza fundamental entre Teucro e Eneas é que, mentres o segundo é un heroe do bando troiano, Teucro, malia a súa liñaxe, tamén ligada á dinastía de Príamo, loita no bando dos gregos. Segundo Bracessi (1984: 15-16), non obstante, estes detalles esváense no marco ideolóxico e no esquema mítico da viaxe fundadora. Sobre o arqueiro Teucro e a súa caracterización como bastardo, medio irmán de Aiax Telamonio e responsable último da súa morte ante o pai, vid. Ebbott (2003), especialmente o capítulo 2: «Teucer, the Bastard Archer».

6 Que non o utilizara xa foi advertido por F. Rubio Álvarez (1956: 48), quen considera tamén que a nómina de fontes a puido tomar Afonso X de Ximénez de Rada. O padre Rubio non entra a considerar se o texto foi descoñecido ou simplemente omitido. 
como «coidadoso recortador de historias orientais $»^{7}$ (De rebus Hispaniae, Prologus, 70: Fernández Valverde 1987: 7), o cal dá a entender que o ten como unha autoridade para asuntos relacionados con Oriente, e desde logo non coa zona extrema do Occidente que é a Península Ibérica. As escasas ocasións en que nos seus textos Ximénez de Rada parece utilizar a Xustino, por exemplo, no episodio das amazonas, en realidade estase servindo doutra fonte, nese caso os Exordia Scithica ${ }^{8}$.

Que acontece na obra historiográfica de Afonso X con respecto a Xustino? O asunto resulta complexo e non moi claro. Por unha banda, a utilización dos Epitoma Historiarum Philippicarum de Pompeio Trogo na obra do Rei Sabio é ampla e diversa: claramente é unha fonte utilizada nas dúas obras afonsinas, por exemplo ao tratar a historia de Elisa/Dido (Primera Crónica General 49-60: Menéndez Pidal 1906: 31-44; General Estoria II, 1, capítulos 370-374 e II, 2, caps. 419-20), a raíña de Cartago, da que fala Xustino no libro $18^{9}$, e de xeito evidente así mesmo ao falar de Sicilia cando introduce o tema do Etna na General Estoria. Na cuarta parte da súa obra de historia universal, antes de narrar as guerras que atinxiron a illa na época de Artaxerxes Asuero, faise un «departimento» da terra de Sicilia (General Estoria Cuarta Parte, 2, 12: Orellana 2009: 179: «Departe la estoria en este logar d’aquella tierra e dize así»). Baixo la estoria decatámonos axiña de que se atopa o texto de Xustino 4, 1-2 (Seel 1985: 46-49) que Afonso segue con notable fidelidade. A lealdade do texto de Afonso X ao longo desta pasaxe ao seu modelo latino, «la estoria» ${ }^{10}$, só se ve truncada, ou modificada, en escasas malia que significativas ocasións, algunhas delas para seguir a Ovidio e os seus comentaristas ${ }^{11}$.

Se Xustino é utilizado nesta pasaxe, aínda que sen mención explícita ao seu nome, en cambio dista de ser un recurso para tomar noticias sobre a prehis-

7 A aposición utilizada polo Toledano para cualificar a Pompeio Trogo é curiosa. Recorda a Ovidio (Ex Ponto 2, 3, 18): «sollicitis supputat articulis», expresión empregada para medir o interese de alguén, «calcula con dedos solícitos». Supputare é un verbo empregado para a idea de contar, calcular, pero tamén para a de podar, recortar.

8 En concreto, nunha versión privativa dunha familia de códices que remontan probablemente a un antígrafo de área napolitana, como demostrei nun traballo recente, De Carlos Villamarín (2019).

9 A versión de Xustino desta historia, que se retrotrae ao historiador Timenio de Tauromene, foi estudada por Olga T. Impey en dous importantes traballos (Impey 1980 e 1982). Cf. así mesmo De Carlos Villamarín (2008).

10 En 15 (Orellana 2009: 184) refírese á mesma fonte como «aquella Estoria de Assiria», para narrar as guerras entre Catania e Siracusa, seguindo de novo a Xustino 4, 3, 4-7. Esta pasaxe das guerras aparece tamén de forma idéntica a Justino en Orosio, adv. pag. 2, 14, quen encabeza o seu relato desta parte coa frase: «Sicilia ab initio patria Cyclopum et post eos semper nutrix tyrannorum fuit».

11 Como acontece noutra mención que se fai á illa de Sicilia e aos seus tres promontorios ao tratar o mito de Proserpina (General Estoria, Primera parte, Génesis; Sánchez-Prieto Borja 2009: 404-405). Xa Irene Salvo García mostrou na súa tese de doutoramento (Salvo García 2012) que a pasaxe do mito de Proserpina da General Estoria é un resumo especialmente abreviado de dúas obras ovidianas, Fastos IV, 418-620, e Metamorfoses 5, 347 ss., que engade algúns detalles á anterior, como son precisamente os nomes dos tres promontorios. Malia que os mesmos afonsinos remiten a Eberardo de Béthune, autor do Graecismus, este non semella ter dado directamente a etimoloxía de Trinacria como tres montículos, aínda que pon o nome como exemplo de uso da palabra «akros» na acepción de monte (Graecismus, 8, 16: «Mons acros atque leuis, ceu Trinacris aut acrozymus»). A súa fonte é en realidade Arnulfo de Orléans. 
toria mítica da Península. Unha explicación pode ser que o texto de Xustino talvez circulou truncado, carente dese libro 44, último da obra, ou mesmo nunha sorte de escolma historiográfica dedicada aos imperios previos ao romano, xustificando así a denominación de historiador de asuntos orientais dada por Ximénez de Rada, ou de «aquella Estoria de Assiria» que din os afonsinos. Talvez, simplemente, Afonso X non quixo asumir ese relato, malia coñecelo. E mesmo quere diverxer del manifestamente, como acontece no tratamento do personaxe de Xerión, outro elemento do pasado mítico peninsular abordado por Xustino, pasado por Isidoro e chegado a Ximénez de Rada, que muda radicalmente mesmo na súa morfoloxía na obra afonsina, pois convértese nun monstro de sete cabezas, fronte ás tres que unanimemente lle asigna a tradición. Sobre este aspecto regresarei en breve. Polo de agora só quero comentar a estrañeza que me segue a causar a omisión das ricas informacións sobre a historia prerromana da Península de Xustino por parte dos colaboradores afonsinos. Se eles coñecían o texto, como demostran coñecer outras seccións del, por que non quixeron incorporalo? Máxime cando a actitude de Afonso X con respecto aos textos latinos é unha actitude humanista, que procura o texto para traducir, que o insire onde é pertinente ou mesmo lle busca o lugar para ser inserido. E en boa medida un dos sinais do cambio de rumbo das historias de España coa chegada do humanismo propiamente dito é xustamente esta, que a prehistoria mítica abandona non o molde, pero si a letra esculpida por Ximénez de Rada, e enche ese molde con datos tomados de Xustino, como sucede por exemplo na obra de Joan Margarit ou Rodrigo Sánchez de Arévalo, no século XV (Rubio Álvarez 1956: 49, De Carlos Villamarín 1995).

Quizais sexa pertinente mencionar, polo momento, a tamén sorprendente ausencia de referencias á obra de Isidoro de Sevilla que ofrece a obra historiográfica afonsina, xa destacada por Luis López Santos (1961). Aínda máis sorprendente é o feito de que a obra do bispo de Sevilla está presente e é utilizada polos afonsinos sen serlle a el atribuída. Os libros 14 e 15 das Etimoloxías de Isidoro aparecen entre os materiais usados nas historias afonsinas baixo o nome de Libro de las Provincias, tal como a crítica recoñece (Solalinde 1934, Lida de Malkiel 1958, González Rolán 1981, Sánchez Prieto Borja 2016). É dicir, cando Isidoro é utilizado non o é como auctoritas, senón baixo un título anónimo, pero en xeral non se recorre a el nin ás súas obras de xeito directo, cando menos en aparencia, nin é invocado polo seu nome agás para falar do seu papel como bispo ou como santo. Esta estraña circunstancia levou a Daniel Eisenberg (1973) a comentar: «A discussion of Alfonso's sources raises problems as well as solves them. How is it that Alfonso knew Isidore's Etymologies, the medieval work by which Spain was best known in Europe, only in a fragmentary version, with the wrong title and no author?». Segundo os estudosos citados, malia que cando menos un dos libros que figuran na listaxe de manuscritos tomados como empréstamo por parte de Afonso X ao mosteiro de Albelda en 1270, considerados por algúns como punto de partida para 
a confección da obra historiográfica ${ }^{12}$, é un exemplar das Etimoloxías (Beer 1894: 50-51, González Rolán 1981), en ningures, nin nas citas, nin mesmo nas fontes da General Estoria de Afonso X, se pode percibir unha alusión a Isidoro de Sevilla como auctoritas. Polo contrario, si hai algunhas mencións na Estoria de Espanna e na General Estoria a Esidro ou Eisidro, ou mesmo San Esidro, como santo. Segundo López Santos, o decrecente papel de Isidoro de Sevilla como autoridade literaria no medievo hispano foi en paralelo ao seu crecente significado e presenza nas fontes historiográficas como santo ${ }^{13}$.

Non se pode logo trazar unha presenza directa do autor visigodo, malia que, en cambio, si poidamos facelo das autoridades citadas por el e que os afonsinos usan de xeito directo, como é o caso de Plinio. É bastante probable que Isidoro e a súa obra fosen xa unha especie de reliquias dun mundo pasado e dun xeito de pensar pretérito para os intelectuais da época afonsina, e que o sabio visigodo fose recordado máis como o santo venerado no reino de León ${ }^{14}$ ca como a meirande autoridade do saber medieval, pero non por iso debemos pensar que a súa obra foi totalmente erradicada do escritorio afonsino. Ao meu xeito de ver, esta puido ser a ringleira sobre a que escribiron nalgúns momentos os colaboradores de Afonso X, a partir da que obtiveron a nómina de autoridades que, como Plinio, como Xustino, puideron logo consultar e traducir de xeito directo, e desde a que apreciaron a forza da etimoloxía como modo de coñecemento das cousas, aínda que a partires dese principio procurasen outras explicacións etimolóxicas desbotando as isidorianas.

\section{XERIÓN}

Quixera, polo de agora, achegarme a un dos personaxes máis fascinantes da secuencia de textos que levamos bosquexada na tradición historiográfica, o de Xerión. Como xa comentei, este personaxe aparece vinculado á historia de

12 Malia que con matices, xa que non hai unanimidade en considerar se este é realmente un punto de partida para a elaboración de materiais para ambas as obras ou habería que consideralo máis ben unha data tardía, cando en realidade habería dúas grandes etapas de elaboración de obras afonsinas, unha marcada polo ano 1250, coa que podería cadrar a confección da Estoria de Espanna, e outra polo 1270, que coincidiría coa redacción da General Estoria. Vid. Cárdenas (1997).

13 O papel de Isidoro como o santo máis prominente na chamada Reconquista cristiá da Península foi estudado coidadosamente e posta de relevo tamén a orixe e as relacións que manteñen entre si os diferentes textos que tratan de Isidoro como unha figura venerable e que tocan a devoción que se lle consagrou no reino de León (Martín 2005, Falque Rey 2015)..

14 Do que o propio Afonso evoca na Estoria de Espanna no importantísimo momento da entrada do seu pai Fernando III na súa amada cidade de Sevilla xusto o mesmo día do aniversario da translación de Isidoro a León, Estoria de Espanna 1125: Menéndez Pidal 1906: 767: «Capitulo de comma el rey don Fernando entro en Sseuilla et de comma fue refibido con grant profesion.; Dia era de la traslaçion de sant Esidro de Leon, arçobispo que fue de Seuilla-en la era de mill et dozientos et ochenta et seys, do andaua el anno de la Encarnaçion del Nuestro Sennor jeshu Cristo en mill et dozientos et quarenta et ocho-quando ese noble et bienauenturado rey don Fernando, de que la.estoria tantos bienes a contado, entro en esa dicha noble çipdat de Seuilla, capital de todo ese sennorio del Andalozia». 
Hispania ou, por mellor dicir, á súa protohistoria, en Xustino 44, 4, 15-16. Dísenos del que reinaba noutra parte de Hispania que tamén está formada por illas («In alia parte Hispaniae et quae ex insulis constat»), facendo alusión ao punto anterior, no que se trataba do reino primitivo de Tartessos (De Carlos Villamarín 1996: 80-92). Dísenos, así mesmo, que era o rei pacífico dun lugar próspero onde o gando se criaba vizosamente, ata o punto de que, por unha parte, a súa figura se evemeriza para facer da súa morfoloxía tripla encarnación de tres irmáns moi ben levados que gobernaban como un único rei, e, por outra parte, incorpórase Hércules ao relato, convertido nun depredador de gandos e riquezas (Xustino 44, 16, Seel 1985: 301):

Porro Geryonem ipsum non triplicis naturae, ut fabulis proditur, fuisse ferunt, sed tres fratres tantae concordiae extitisse, ut uno animo omnes regi viderentur, nec bellum Herculi sua sponte intulisse, sed cum armenta sua rapi vidissent, amissa bello repetisse [Ademais din que o mesmo Xerión non foi de natureza tripla, como se conta nos relatos, senón que existiron tres irmáns de tan grande entendemento que mesmo parecía que todos gobernaban cun único espírito, que non levaron a guerra a Hércules por vontade propia, senón que ao veren que lles roubaban os seus gandos, foron procurar coa guerra o que perderan].

Este Xerión visto como rei bo sometido ás razzias dun Hércules depredador coincide co Xerión do que nos fala Braccesi situado no Epiro, «ove la tradizione fa di Gerione un re indigeno» (Braccesi 1984: 24, De Carlos Villamarín 1996: 97, Chevallier 1976), e aseméllase moito ao Xerión divindade bondadosa e propiciatoria de oráculos situada en lugares como Abano, nos arredores de Padua, e Agirio, en Sicilia. Segundo Braccesi (1984: 24), ese culto a Xerión podería ser un eco da lembranza de depredacións de gando no seo dunha loita entre o elemento colonial pregrego, representado por Heracles, contra os reis indíxenas. A lenda de Xerión, vinculada á de Heracles en todos estes casos, expresaría a existencia dun substrato orixinario non grego (celta, para algúns estudosos, González García 1997: 18-48) que sería asimilado á lenda grega do Heracles clásico, pero co papel cambiado ${ }^{15}$, e falaría desde un punto de vista historicista dunha sorte de ruta prehistórica que uniría o norte do Adriático, por unha parte, con Sicilia, facendo un alto no Epiro, e, por outra, coa Península Ibérica, o cal se constataría en tempos posteriores coa introdución de lendas ligadas ás viaxes dalgúns heroes homéricos, nomeadamente Antenor e os Antenóridas, Diomedes, Anfíloco e Teucro ${ }^{16}$, relacionadas así mesmo con esta xeografía.

15 «per giustificare le razzie dell'elemento coloniale greco ai danni del indigeno, il dio, da divinità benefica, diviene demone mostruoso connesso con il regno delle tenebre» (Braccesi 1984: 24-25).

16 Ademais do expresado en De Carlos Villamarín (1992: 92-105), resulta fundamental Braccesi (1984: 33- 43: «Gli Antenoridi: dal Veneto all’Iberia»). 
Independentemente dos posibles contactos de época micénica e, máis tarde, de tempos coloniais atenienses e posteriormente romanos, entre estes lugares, interésame a certeza do que os textos comentan con respecto á figura de Xerión. O papel benéfico e a evemerización deste inicial monstro de tres cabezas mantense en Isidoro, quen utiliza case ao pé da letra a Xustino (Orig. 11, 3, 28: Oroz/ Casquero 1994: 52):

Dicuntur autem et alia hominum fabulosa portenta, quae non sunt, sed ficta in causis rerum interpretantur, ut Geryonem Hispaniae regem triplici forma proditum. Fuerunt enim tres fratres tantae concordiae ut in tribus corporibus quasi una anima esset [Pero cóntanse tamén outros prodixios fabulosos de homes, que non existen, pero interprétanse como ficcións nas causas das cousas, como o que se transmitiu de que Xerión, o rei de Hispania, tiña unha forma tripla. É que foron tres irmáns de tan grande entendemento que era como se houbese unha única alma en tres corpos].

Mantense, así mesmo, nel a indefinición do lugar xeográfico concreto co que se vincula a figura, ou máis ben, fronte a Xustino, pódese afirmar que Isidoro o vincula coa totalidade de Hispania. A interpretación evemerista de Xerión permanece en Ximénez de Rada, para quen el era o rei de tres provincias: Bética, Galicia e Lusitania (De rebus Hispaniae 1, 4, 19: Fernández Valverde 1987: 15):

Erat autem tunc temporis in Hesperia princeps quidam qui Gerion uocabatur et habundabat gregibus et armentis et habebat tria regna que nunc dicuntur Gallecia, Lusitania, Bethica: unde et iste Gerion cum esset alias fortis et ferox, triplex describitur fabulose [Había daquela en Hesperia un príncipe que se chamaba Xerión e abundaba en rabaños e gandos e tiña tres reinos que agora se chaman Galicia Lusitania e Bética: de onde tamén ese Xerión, que polo demais era forte e fero, se describe fabulosamente como triplo] ${ }^{17}$.

O cal coincide coa versión dada por Afonso X na General Estoria (II, 2; Fernández Ordóñez 1992: 131-132). E malia que aquí o Toledano o cualifíca de «ferox», tamén se mantén a idea non tanto de que Xerión fora un rei pacífico, como a de

17 Segundo Estévez Sola (1990), esta versión pola cal Xerión é cabeza de tres reinos procede do comentarista Iohannes Anglicus, quen di expresamente: «Gerionis caput est in triple regno/cuius diuicie preda fuere uiro», pero teño que advertir que xa en Servio, o famoso comentarista de Virxilio do século v (In Aen, 7, 662), Xerión goberna tres entidades xeográficas, aínda que estas se identifican coas Baleares: «Geryones rex fuit Hispaneae qui ideo trimembris fingitur, quia tribus insulis praefuit, quae adiacent Hispaniae: Baliaricae minori et maiori et Ebuso». 
que Hércules devastou a Península ao seu paso. En primeiro lugar, Xerión é vencido por Hércules nun lugar indefinido, talvez nalgunha desas provincias occidentais que gobernaba, pero esa vitoria fai entrar en escena a Galicia (De rebus Hispanie 1, 4, 29: Fernández Valverde 1987: 15 ):

Contra hunc pugnauit Hercules, et repetito bello ferocem uirtute domuit et prostrauit priuatum uita, patrimonio et armentis, optentamque partem illam Hesperie populis qui secum a Galacia uenerant captam tradidit habitandam; unde et a Galatis Galletia V $\underline{\text { a }}$ prouincia Hyspanie nomen accepit, licet ab aliquibus alia causa nominis assignetur [Contra este loitou Hércules, e repetida a guerra domou coa súa virtude ao fero e dobregouno, privado de vida, de patrimonio e de gandos, e entregou a parte aquela que obtivo de Hesperia, tras capturala, aos pobos que viñeran desde a terra dos gálatas para que a habitasen; de onde, a partir dos gálatas, Galicia, quinta provincia de Hispania, recibiu o seu nome, aínda que por parte dalgúns se lle asigne outro motivo ao nome].

Como xa adiantamos, Afonso X concorda ao pé da letra con Ximénez de Rada neste punto, ao atribuír a fundación de Galicia aos gálatas (Estoria de Espanna 7). E, como conclusión das incursións de Hércules en Hispania, e antes de deixar ao seu cargo a Hispán, o Toledano escribe (De rebus Hispaniae 1, 5, 46: Fernández Valverde 1987: 17):

Et optenta Hispania, immo uerius desolata, que a sui principio, quam primum Cetubeles habitarunt, satis prospera felicitate gaudebat, infelices populos, quos longa quies inhermes fecerat et ignauos, Grecorum iugo, qui naturaliter subditis sunt infesti, gladius Herculis subiugauit... [E obtida Hispania, ou máis ben asolada, a que desde a súa orixe, cando a habitaron os Cetubeles, gozaba dunha fecundidade abondo próspera, a espada de Hércules someteu ao xugo dos gregos, que de natural son crueis cos seus súbditos, a uns pobos desgraciados, aos que unha longa paz fixera inermes e preguiceiros].

Polo tanto, malia que Ximénez de Rada cualifica a Xerión como «ferox» e cre que esa ferocidade é vencida pola «virtus» de Hércules, considera que a ocupación de Hércules, e con el a «servitus» dos gregos baixo a que Hispania cae, e que continuará coa opresión dos romanos, é un feito lamentable, como expresa tamén repetidamente na súa Historia Romanorum, xa, por exemplo no seu Prologus (Fernández Valverde 1979-80: 159): 
Quia direptiones Herculis, quas gens misera pertulit Hesperorum, in superioribus capitulis declaraui, quae Romani, Vandali et Sueui, Alani et Silingui, et Arabes Mahometi, et qualiter Hispanias inuaserunt, et quae ei multiplicata supplicia addiderunt, prosequi dignum duxi... [Porque xa expliquei os saqueos de Hércules que soportou a pobre xente dos Hésperos en anteriores capítulos, considerei digno proseguir os dos romanos, vándalos e suevos, alanos e silingos, e os árabes de Mahoma, e como invadiron as Hispanias, e que castigos multiplicados engadiron a ese].

Baixo a concepción da historia do arcebispo de Toledo subxace con toda probabilidade un núcleo de historiografía «mozárabe» que se orixina na Península, xa visible na chamada Chronica Pseudoisidoriana, un texto datable no século XII (González Muñoz 2000), e que semella aínda máis perceptible en Afonso X, como veremos. Na mesma construción do personaxe de Xerión púidose superpoñer ao legado isidoriano a imaxe de Alión, presente na chamada Crónica del Moro Rasis (LII, Catalán/De Andrés 1975: 127), na que se fala da morte de «Alión a tres migeros de la çibdat que agora llaman la Curuña, a do el fizo el conçilio en Galizia» (Catalán 1975, De Carlos Villamarín 1996: 287-291, González García 1997: 112-124). Pero tamén é perceptible unha visión que eu mesma hai anos definira como «clasicista». A imaxe que Ximénez de Rada ofrece de Hércules, sobre os recordos isidorianos que sen dúbida alentan tamén a súa obra, un de cuxos referentes é a Historia Gothorum de Isidoro, torna de xeito obvio e confeso ás fontes literarias antigas, a Ovidio, a Virxilio ${ }^{18}$. Eu non descartaría que Ximénez de Rada estivese animado neste sentido polo coñecemento de primeira man dos clásicos que puido ter durante as súas estadías en Italia, onde tamén puido ser influído pola proliferación de voces cívicas na procura de orixes míticas vinculadas ao pasado glorioso e aos heroes fundadores das cidades e repúblicas italianas, especialmente as do Véneto e da Toscana, á imaxe e semellanza da mesma Roma (Benes 2011).

Sospeito que este camiño trazado polo arcebispo de Toledo contra 1246 (Jerez Cabrero 2003) foi continuado con meirande empeño, e nun sentido máis fondo, por Afonso X, a quen o seu labor na recollida e tradución de textos antigos pode facer análogo ao de calquera humanista mesmo posterior no tempo, como tentarei demostrar. Por outra banda, a Estoria de Espanna de Afonso X presenta algún elemento orixinal sobre as primeiras etapas da vida peninsular cuxa acción transcorre na actual Galicia, e máis concretamente vinculada á que moitas testemuñas presentan como a atracción sobranceira, protagonista de relatos máis ou menos fantásticos, visible en

18 As citas de Ximénez de Rada son literais: a Virxilio, Aen 7, 661-663; a Ovidio, Met. 9, 184-185 e Her. 9, 91-92. Curioso que estas últimas fontes, as ovidianas, foran traducidas practicamente na súa integridade ao castelán polo equipo afonsino para confeccionar as historias, sobre todo a General Estoria. 
documentos e en historias, o Faro da Coruña. Como construción na que alenta o carácter antigo e venerable podería pensarse que ocupa un papel análogo ao que na mesma obra afonsina ten o acueduto de Segovia; é dicir, a condición de monumento que causa tanta estrañeza como marabilla e que se relaciona con algún tipo de personaxe especial. Ximénez de Rada refírese ao monumento máis vagamente, como unhas torres, vinculándoo á presenza de Hércules «in finibus Hesperie» pero só o denomina «Gades Herculis», e vincula máis adiante a construción, ou reconstrución («extruxit»), desas torres «in pharo Gallecie et in Gadibus» ao delegado de Hércules en Hispania, Hispán (De rebus Hispaniae 1, 4, 16-19; 1, 7, 5-6). Afonso X aposta por atribuír claramente a construción do faro a Hércules, pero innova con respecto á súa fonte ao asociar este personaxe, asemade, á fundación da cidade da Coruña. Tamén ampliará as noticias do Toledano dándolle a Espán, convertido en sobriño de Hércules, a función de poñer un espello no cumio do faro, como veremos. Afonso X dota a Hércules dun protagonismo meirande do que lle outorgara o Toledano, e iso tanto na Estoria de Espanna como na General Estoria; as cales, por outra banda, non sempre concordan entre si, polo que é razoable pensar que ambas as dúas, sobre a base da historia de Ximénez de Rada, utilizaron cada unha pola súa conta o material de raíz hispanoarábiga que previamente os colaboradores afonsinos traduciran para ter ao dispor da confección dun e outro proxecto historiográfico (Fernández Ordóñez 1992: 120-138, 193-202).

Por unha banda, Afonso X na Estoria de Espanna introduce o personaxe de Xerión, segundo xa comentei, transformado en rei de sete provincias correspondentes ás súas sete cabezas lendarias (Primera Crónica General 7: Menéndez Pidal 1906: 9) e en concreto cualificado como:

un rey muy poderoso auie en Esperia que tenie la tierra desde Taio fasta Duero, e por que auie siete prouincias en su sennorio fue dicho en las fabliellas antiguas que auie siete cabeças; y este fue Gerion, y era gigante muy fuerte y muy liger, de guisa que por fuerça derecha auie conquista la tierra e auien le por fuerça a dar los omnes la meatad de quanto auien, tan bien de los fijos e de las fijas cuemo de lo al, e a los que no lo querien fazer mataualos. E por esto era muy mal quisto de todas las gentes, mas no osauan yr contra el por que no auie y qui los deffender...

Cabe recordar, que, en cambio, na General Estoria Xerión segue a ter tres cabezas, como na case unanimidade das fontes. Por momentos chego a sospeitar se non se fundirían na innovación da Estoria de Espanna afonsina elementos tomados dun curioso personaxe presente nun tamén curioso texto da tradición historiográfica hispana, vinculado expresamente a Galicia, a chamada «Historia de Octaviano e Septemsídero». Este texto, editado por Juan Gil (1971) e por Díaz y Díaz (1972-74 e 1985), 
está copiado no chamado Códice de Roda, o manuscrito da Real Academia da Historia 78 datado no século XI, que contén na súa primeira parte a obra de Orosio e, na segunda, unha serie de textos diversos, entre os que predominan os de corte historicista, ademais dun dossier de xenealoxías finalizado cunha imaxe da Epifanía, análogo ao que adoitan presentar os beatos e algunha biblia visigótica (De Carlos Villamarín 1996 e 2010). O texto que nos ocupa fala da loita entre Octaviano e Septemsídero; o primeiro é rei de Toledo e o segundo habita nun lugar indeterminado, pero relacionado con Galicia. Dise del que é «maritus de Iherie, pater de Bracaro et de Flavio et de Teoderico et de Galaa et de Gemulus et de Cesario, qui fecit Zesarea et Faro». Tras a loita e a inopinada vitoria de Septemsídero, este instálase coa familia en Lugo, e os fillos fanse fundadores epónimos de cidades da Gallaecia ${ }^{19}$ :

Bracarus Bracara, Flavius Flavias, Teudericus Tude super mare, Galaa portus Galee: Sequarius fuit mortuus in Tamare ibi dicunt portus Sequarii. Gemulus erat fortiosus, in singulas manus binas portavat columnas; ipse fecit bobata sci Petri et celbas super Aquas Caldas et ponte in Mineo. Et Cesarius super hinc resonat... [Brácaro Braga, Flavio Chaves, Teodorico Tui sobre o mar, Gala Portugal: Secuario foi morto no Tambre, no lugar que chaman Porto de Sigüeiro. Xemulo era ben forte, en cada man levaba dúas columnas; el fixo a bóveda de San Pedro e Celas sobre Caldas e unha ponte no Miño. E Cesáreo destaca por riba deste].

Resúltame curioso que a loita territorial, como na Estoria de Espanna, se resolva neste texto nun combate singular entre os reis. Pero tamén que Gemulus teña resonancias mesmo iconográficas con Hércules portando senllas columnas (Rodríguez Porto 2017), ou que se asocie a outro dos fillos de Septemsídero, Cesarius, co faro e, indirectamente, con Xulio César. Chama tamén poderosamente a atención que a muller de Septemsídero responda ao nome, de resonancias eponímicas, de Iheria, e que a filla de Hispán e muller de Pirus ou Piro, un dos primitivos reis da Península e epónimo dos montes Pirineos na Estoria de Espanna 8, se chame Liberia. Tampouco me parece a nómina de pobos que ocuparon Hispania segundo a Laus Spanie do folio 198r do Códice de Roda (De Carlos Villamarín 1996: 301-323) allea ao concepto dos «sennorios» da Península expresado na historia hispánica afonsina, é dicir, que Hispania se conciba como un soar que será sucesivamente dominado por diferentes «sennores», reinos ou pobos, sete no caso do texto citado do Códice de Roda. Cabe lembrar que este é

19 Remito o lector aos estudos citados para unha avaliación e posibles identificacións dos topónimos suxeridos no texto. A edición citada de Gil vén completada por un estudo de Isidoro Millán que incide nestes aspectos. 
aparentemente o principio vertebrador da Estoria de Espanna afonsina ${ }^{20}$. Sería prolixo tratar de todas estas cuestións, tan complexas, neste lugar, pero cando menos quero que quede apuntado para ulteriores investigacións. O Códice de Roda contén, como digo, as Historias adversus paganos de Orosio e materiais cuxa procedencia se podería asignar a moi distintos lugares da Península, sen que a eles sexan alleos os puntos de vista que poderían relacionalos con medios árabes. Que chegase a ser consultado polos colaboradores afonsinos, ou que estes coñecesen por outra vía os textos nel contidos, non me parece unha hipótese que poidamos desbotar.

\section{HÉRCULES}

É precisamente a tiranía exercida por este Xerión de sete cabezas, no que percibimos así mesmo trazas do mítico rei Minos de Creta (combatido, por certo, polo outro grande heroe vencedor de monstros, Teseo), quen atrae a un Hércules debuxado cos trazos da nobreza e da xustiza (Primera Crónica General 7: Menéndez Pidal 1906: 9-10):

[...] et cuando sopieron que Hercules uinie, enuiaron le dezir, que el, que tantos buenos fechos fiziera e tantos omnes sacara de premia e de mal sennorio, que acorriese a ellos, e quel darien toda la tierra. Quando esto oyo Hercules, plogol mucho e fuesse pora alla; ca maguer ell era del linage de los gigantes e muy fuerte, no era por esso omne cruo ni de mala sennoria, ante era muy piadoso a los buenos y muy brauo e fuert a los malos; e quando oyo las querellas daquellas yentes, doliose dellas e fuesse pora ellos. E quando Gerion lo sopo, fuesse con sus huestes pora aquel logar o fue despues poblada la cibdat que dizen Crunna, que era entonces yermo. Hercules enuio dezir a Gerion que las yentes no auien por que matarse ni por que lazrar, mas que lidiassen ellos amos un por otro; y el que uenciesse, que fuesse toda la tierra suya. E Gerion atreuiendose en su ualentia, e demas que era mayor que el, dixo quel plazie. E lidiaron tres dias que nos podien uencer; en cabo uencio Hercules e cortol la cabeça. E mando en aquel lugar fazer una torre muy grand; e fizo meter la cabeça de Gerion en el cimiento, e mando poblar y una grand cib-

20 A idea de que o principio estruturador da Estoria de Espanna é a sucesión de «sennoríos» foi formulada por Menéndez Pidal. No fondo podería resultar da incorporación e organización nun único texto das diferentes obras de Ximénez de Rada dedicadas non só aos godos, senón tamén aos romanos, vándalos, suevos e árabes; é dicir, aos pobos vinculados política e territorialmente con Hispania. Cf. Fernández Ordóñez (1992: 19-26). 
dat $^{21}$, e fazie escreuir los nombres de los omnes e de las mugeres que y uinien poblar, y el primero poblador que y uino fue una muger que auie nombre Crunna, e por essol puso assi nombre a la cibdat.

A torre será rematada por un sobriño de Hércules, o rei Espan, vinculado así mesmo coa construción do acueduto de Segovia e coa poboación e establecemento de monumentos en Cádiz, e encarnación do Hispán creado por Ximénez de Rada en De rebus Hispaniae 1, 7, malia que para o Toledano este personaxe non tivese vínculo familiar con Hércules. Segundo Afonso X (Primera Crónica General, 9: Menéndez Pidal 1096: 11):

Espan, sobrino dErcules, que finco por sennor en Espanna, anduuo por la tierra e fizo la poblar y endereçar, ca era muy maltrecha y destroyda por la grand guerra que fiziera Hercules; e com era omne sabio y entendido, soposse apoderar della, e poblo los puertos de la mar e otrossi logares en las montannas, por o entendio que podrie uenir danno dotras yentes de la tierra; e poblo muy grandes uillas y e buenas, e fizo y lauores marauillosas... E acabo la torre del Faro que començara Hercules, que es cabo a la Crunna; e com era omne muy sabidor, fizo fazer un grand espeio, que ueyen en el uenir las naues por el mar de muy luenne, e pusol en somo daquella torre, y esto fizo el por aguardar se dotras yentes sil uiniessen guerrear por mar.

O perfeccionamento por parte de Espán do faro coa incorporación do espello revelarase ben necesario no famoso episodio da invasión dos «almuiuces» que Afonso trata no capítulo 14 da Estoria de Espanna e que foi estudado en varias ocasións pola súa probable relación con lendas de orixe irlandesa ou xa filtradas pola visión hispanoarábiga (Wikander 1966, Fernández Ordóñez 1992: 198-202, González García 2012). A historia do espello preséntase xa antes, por exemplo no texto denominado Trezenzonii de solistitionis insula magna, unha pequena xoia datada no século XI, na que se atribúe tal marabilla ao farum Brecantium (Díaz y Díaz 1985), pero pode ter a súa base na famosa descrición de Hispania de Orosio (Historias adversus paganos 1, 2, 70-72) $)^{22}$, que chama tamén a atención pola relación que nela se establece entre os distintos ángulos da Hispania trigona, logo vinculados con construcións atribuídas

21 A letra cursiva é miña.

22 É preciso ter en conta que a obra de Orosio (s. v) foi traducida ao árabe no século x (Catalán 1975, Fernández Ordóñez 1992: 121) e pasou a incorporarse aos devanditos relatos e historias compostas na Península ou que circularon nela nun medio árabe, de onde as puideron tomar Ximénez de Rada e Afonso $\mathrm{X}$, sexa este por mediación de aquel, sexa, nalgunhas pasaxes, de xeito independente polo Rei Sabio. Inés Fernández Ordóñez (1992: 185-202) observa así mesmo que o detalle do espello do faro recorda extraordinariamente a descrición do faro de Alexandría feita na General Estoria I e baseada en al-Bakri, unha fonte hispanoarábiga recoñecida tamén para ambas as dúas obras históricas de Afonso X. 
a Hércules ou a personaxes relacionados con el, e que asimilan case desde sempre o extremo da Gallaecia con Gades ${ }^{23}$. Esta outra cidade marca tamén un fito na xeografía peninsular e nas andanzas de Hércules na visión de Afonso X, quen por riba introduce nas conquistas deste personaxe unha especial mención á súa amada cidade de Sevilla, noticia que recolle tamén na General Estoria (II, 2), aínda que pouco máis adiante a amplía atribuíndolle a Hércules, ademais, a construción de «una torre en que puso una imagen fecha por el saber de las estrellas, e tenie la mano tendida contra el mar». Na Estoria de Espanna este detalle desenvólvese para formar un relato máis minucioso (Primera Crónica General 6: Menéndez Pidal 1906: 8-9): «e porquel semeio que aquel logar era muy vicioso y estaua en el comienço doccident, fizo y una torre muy grand, e puso ensomo una ymagen de cobre bien fecha que cataua contra orient e tenie en la mano diestra una grand llaue en semeiante cuemo que querie abrir la puerta, e la mano siniestra tenie alçada e tenduda contra orient e auie escripto en la palma: estos son los moiones de Hercules...».

Tamén segundo a Estoria de Espanna, que novamente debe a súa información neste sentido a fontes hispanoárabes, Hércules é o que avista o lugar onde tempo máis tarde será fundada Sevilla e ante a profecía do seu «estrellero» Atlas de que sería outro grande home quen erixiría alí unha cidade, Hércules decide deixar nese lugar un monumento conmemorativo que, efectivamente, será atopado tempo máis tarde por Xulio César ${ }^{24}$. Este feito é lembrado na tradición manuscrita cando menos por unha miniatura (El Escorial, ms. Y.I.2, f. 5r) que reproduce o que o texto indica; é dicir, que o monumento é unha estatua erixida «sobre seis pilares de piedra y una losa de mármol» (Fernández Ordóñez 1992: 125, Rodríguez Porto 2017: 247-250) na que figura esta inscrición: «AQVI:SERA:POBLADA:LA:GRANT:CIBDAT:».

Ademais de lembrar case ao pé da letra a secuencia de feitos da construción do faro e da fundación e poboamento da cidade da Coruña por Hércules, utilizando unha variante desa mesma frase profética, e mando poblar y una grand cibdat, este relato que, sen atinxir directamente ás «Antigüidades da Gallaecia», axuda

23 Non podo deixar de evocar neste punto un texto de Xordanes no que se di que o promontorio da Gallaecia, neste caso comparado co de Lisboa, na medida en que ambos os dous son confundidos por algúns con illas do Océano, posúe un templo de Hércules (Getica 1, 7): «Et sunt iuxta fretum Gaditanum haut procul una Beata et alia quae dicitur Fortunata. Quamvis nonnulli et illa gemina Galliciae et Lysitaniae promuntoria in Oceani insulas ponant, in quarum una templum Herculis, in alia monumentum adhuc conspicitur Scipiones, tamen, quia extremitatem Galiciae terrae continent, ad terram magnam Europae potius quam ad Oceani pertinent insulas» [E hai a carón do mar de Gades, non lonxe, unha illa que chaman Feliz e outra que chaman Afortunada. Aínda que algúns poñan entre as illas do Océano aqueles dous promontorios xemelgos de Galicia e Lusitania, nun dos cales se ve aínda un templo de Hércules, no outro un monumento de Escipión, pero, como se estenden ata o extremo da terra de Galicia, pertencen á grande terra de Europa, máis ca ás illas do Océano].

24 Que o ciclo das andanzas e fundacións de Hércules é un elemento narrativo importante na concepción afonsina da historia peninsular vén destacado polo que nos deixa percibir o truncado ciclo de ilustracións dun dos manuscritos da redacción orixinaria da Estoria de Espanna, El Escorial ms. Y.I. 2 (Rodríguez Porto 2017). Nel pódese apreciar, así mesmo, unha ilustración de Hércules (f. 4r) que, a xuízo de Rodríguez Porto (2017: 243), «a sophisticated example of the rinascita dell'antico before the canonical Renaissance, is a case in point of this attitude towards ancient culture». 
a entender mellor o marco imaxinario no que esas se conciben, esta imaxe e o seu texto achegan unha información valiosísima. Este é un elemento de novo vinculado á convivencia co legado antigo na Península, algo xa perceptible na obra de Ximénez de Rada, pero tamén creo que a admiración e o crecente recoñecemento do seu pasado parecen especialmente evidentes conforme o rei vai coñecendo unha cidade como a Sevilla recentemente reconquistada. Pensamos moitas veces na fascinación que tivo que causar en tantos ollos a visión das construcións, monumentos e recordos dos moitos séculos de ocupación árabe nesa cidade, como no resto de Al-Andalus. Pero non debemos deixar de pensar no impacto que tivo que provocar coñecer tamén a presenza dos vestixios romanos que forzosamente tiveron que estar aínda presentes e vivos no territorio, moi en especial no urbano, e foron obxecto de constante reutilización mesmo para edificar palacios árabes (Rodríguez Porto 2017: 243). En definitiva, ao conquistar seu pai unha das grandes cidades de Al-Andalus, Afonso entra en contacto coa gran cidade da Bética, esa provincia que viu nacer a emperadores como Traxano, pero tamén a romanos distinguidos no cultivo das letras, nomeadamente a familia dos Anneos de Córdoba, un dos cales, Lucano, é profusamente utilizado na General Estoria. Cabería mesmo preguntarse se o relativo desleixo co que se trata a personalidade literaria de Isidoro de Sevilla, como antes vimos, podería deberse xustamente á toma de conciencia que Afonso $\mathrm{X}$ fai dos personaxes literarios romanos antigos, ao tempo que se redescobren as súas pegadas artísticas e visuais en Sevilla. Desde ese punto de vista, Isidoro válelle ao Rei Sabio como santo, pero non como figura literaria, eclipsado talvez polo recoñecemento de figuras que con certeza estaban representados en bustos e imaxes, e entre os cales tivo que figurar tamén Séneca, que, non o esquezamos, foi outro gran cultivador da imaxe de Hércules.

Pero é que, por outra banda, a ilustración que toma como motivo unha inscrición cuxo carácter é ademais profético revela un aspecto híbrido que a fai tan importante como, ao tempo, conmovedora. A miniatura imita os caracteres epigráficos e a disposición dunha inscrición romana, coa súa letra capital, cos seus puntos de separación, con todo o verismo, por así dicir, de quen quere reproducir algo que está á vista, pero está escrita en castelán. Curiosamente, tal como noutros casos Afonso $\mathrm{X}$ reproduce na súa obra poemas en latín, sen ir máis lonxe o que abre a Estoria de Espanna, nesta ocasión tanto o autor do texto como o seu fiel ilustrador traducen a suposta inscrición do latín que garantiría, coma quen di, un meirande realismo. Esta actitude lembra a que Roberto Weiss (1989: 168-194) evoca como propia dos primeiros humanistas italianos ${ }^{25}$, antes de que a epigrafía pase a ser considerada un obxecto de estudo en si mesma polo seu valor de fonte para a historia. Se a inscrición atribuída

25 O anónimo autor da Cronacha di Partenope pedíralle ao médico Niccolò di Deoprepio, procedente de Reggio Calabria, que lle traducise unha inscrición do grego ao latín posta no frontispicio do templo dos Dioscuros en Nápoles para inserila na súa obra. Isto sucede na primeira metade do século XIV. Segundo Weiss (1989: 32), «questa tradizione costituisce un punto di partenza: molto probabilmente infatti è la prima traduzione di un’epigrafe greca classica e per trovarne un’altra bisogna giungere al Quattrocento». 
a Hércules na Estoria de Espanna se traduce é porque non existe un distanciamento abondo con respecto a ela e o seu carácter de presunta pegada e testemuña, senón que se convive con ela dun xeito admirativo, pero natural, e así é tamén utilizada para apuntalar un relato en que Hércules se constitúe na peza lexitimadora dun dominio civilizador e precursor, profético e sempre vinculado á preexistencia, no mundo real, de monumentos romanos que son reinterpretados para dotalos de máis antigüidade e ao tempo dun enlace sinxelo co mesmo tempo dos romanos, como exemplifica a función de Xulio César en canto herdeiro das empresas hercúleas.

\section{EPÍLOGO}

A visión das «Antigüidades da Gallaecia» de Afonso X constata a progresiva desaparición do discurso derivado de Xustino arredor dos primeiros reis hispánicos, sobre o que prima o bosquexo un tanto parcial trazado por Ximénez de Rada, no que este lugar da Península ten certo papel aínda vinculado a Xerión, pero no que novos elementos, de probable procedencia arábiga, entran a configurar unha visión do pasado marcada pola existencia de monumentos, e entre eles o salientable faro da Coruña. Este, ao mesmo tempo, vaise unindo á figura de Hércules, de xeito aínda impreciso no Toledano, e claramente en Afonso X, sempre conservando por iso a relación con outro lugar da Península que xa chamara a atención dos xeógrafos antigos pola súa condición de extremo do mundo, Gades. O descubrimento por parte de Afonso X da Bética acentúa o desexo e a necesidade de dar explicación ao novo mundo que se abre ante el en forma de estatuas, inscricións e mais monumentos do rico pasado romano desta provincia. Con respecto a «Galizia», o faro ofrecerá enigmas que xa se atopan en textos anteriores cuxa pegada na obra de Afonso $\mathrm{X}$ dista de estar clara, pero que coinciden en atraer a atención cara a este monumento dos tempos pasados, así como en explicar talvez episodios históricos difíciles de situar pero que seguramente apelan a invasións marítimas, como dá a entender o capítulo dedicado aos «almuiuces». Afonso móvese, logo, entre o mundo das tradicións literarias e a experiencia dun universo novo e por descubrir, que virá na súa obra tamén da man doutras novas tradicións literarias, coa cantidade de textos que baixo a súa autoridade son procurados, lidos, traducidos e incorporados para enriquecer e acrecentar a súa portentosa obra historiográfica. A súa actitude, polo tanto, navega entre a prosecución de liñas literarias e documentais preexistentes, nomeadamente a de Ximénez de Rada, e o novo coñecemento de textos antigos, unha liña tamén marcada de xeito incipiente polo Toledano, que o Rei Sabio levará a un estado pioneiro na literatura europea, compartindo desde primeira hora e adiantándose, nalgún caso en medio século, a actitudes e a feitos que podemos percibir na Italia do primeiro humanismo. 


\section{REFERENCIAS BIBLIOGRÁFICAS}

- ANDERSOn, Benedict (1983): Imagined Communities: Reflections on the Origins and Spread of Nationalisms, London/New York, Verso.

- BEER, Rudolph (1894): Handschriftenschätze Spaniens, Wien, F. Tempsky.

- Benes, Carrie E. (2011): Urban Legends: Civic Identity and the Classical Past in Northern Italy (1250-1350), Pensilvania, Penn State University.

- BraCCesi, Lorenzo (1984): La leggenda di Antenore, da Troia a Padova, Padova, Signum Edizioni.

- CÁrdenas, Anthony J. (1997): «The Myth of Hercules in the Works of Alfonso X: Narration in the Estoria de España and in the General estoria», Bulletin of Hispanic Studies, 44, 5-20.

- Carlos Villamarín, Helena de (1995): «Mitos fundacionales de la Península Ibérica: entre la historiografía medieval y la del temprano humanismo», Euphrosyne, 23, 247-258.

- Carlos Villamarín, Helena de (1996): Las Antigüedades de Hispania, Spoleto, CISAM.

- CARlos Villamarín, Helena de (2008): «Interpreting the Past: Some Medieval Texts on Trojan Matter», The Journal of Medieval Latin, 18, 101-116.

- Carlos Villamarín, Helena de (2011): «El Códice de Roda como compilación de voluntad historiográfica», Edad Media. Revista de Historia, 12, 119-142.

- Carlos Villamarín, Helena de (2019): «Rodrigo Jiménez de Rada y la compilación historiográfica del códice de Bamberg Hist. 3», Traditio, 74, 249-270.

- Catalán, Diego (1962): De Alfonso X al conde de Barcelos. Cuatro estudios sobre el nacimiento de la historiografía romance en Castilla y Portugal, Madrid, Gredos.

- Catalán, Diego/Ma Soledad de Andrés (1975): Crónica del Moro Rasis, Madrid, Gredos.

- Chevallier, Raymond. (1976): «Les mythes ou le temps de la Protohistoire: l'exemple de l'Italie du Nord», en Aiôn. Le temps chez les Romains, Paris, Picard, 29-54.

- Díaz y Díaz, M. C. (1985): Visiones del más allá en Galicia en la Alta Edad Media, Santiago de Compostela, Bibliófilos Gallegos.

- DíAZ y Díaz, M. C. (1972-74): «Tres ciudades en el Códice de Roda: Babilonia, Nínive y Toledo», Archivo Español de Arqueología, 45-47, 125-130; 251-265.

- Еввотт, Mary (2003): Imagining Illegitimacy in Classical Greek Literature, Harvard University, Center for Hellenic Studies (http://nrs.harvard.edu/urn-3:hul.ebook:CHS_Ebbott.Imagining_Illegitimacy_in_Classical_Greek_Literature.2003) [última consulta: outubro de 2021]. 
- EISENBERG, Daniel (1973): «The General Estoria. Sources and Source Treatment», Zeitschrift für romanische Philologie, 89, 206-227.

- Estévez Sola, Juan Antonio (1990): «Aproximación a los orígenes míticos de España», Habis, 21, 139-152.

- Falque Rey, Emma (2014): «La translatio beati Isidori y el testimonio de Lucas de Tuy», Studium Legionense, 55, 149-180.

- FeRnándEZ ORDóÑEZ, Inés (1992): Las Estorias de Alfonso el Sabio, Madrid, Istmo.

- Fernández Valverde, Juan (ed.) (1979-80): «Roderici Ximenez de Rada Historia Romanorum», Habis, 10-11, 157-182.

- Fernández Valverde, Juan (ed.) (1987): Roderici Ximenez de Rada Historia de rebus Hispaniae sive Historia Gothica, Corpus Christianorum Continuatio Medievalis 72, Turnhout, Brepols.

- Gil FernándeZ, Juan (1971): «Textos olvidados del Códice de Roda», Habis, 2, 165-178.

- González García, Francisco Javier (1997): Hércules contra Gerión. Mitos y leyendas de la Torre de Hércules, vol. I, A Coruña, Vía Láctea Editorial.

- González García, Francisco Javier (1998): Hércules contra Gerión II. Mitos y leyendas de la Torre de Hércules, vol. II, A Coruña, Vía Láctea Editorial.

- GonZÁlez García, Francisco Javier (2012): «Las fuentes del relato de la invasión de los almujuces en la Estoria de Espanna de Alfonso X el Sabio», Mélanges de la Casa de Velázquez, 42:1, 185-203.

- GonzÁlez Muñoz, Fernando (ed.) (2000): La Chronica Gothorum Pseudoisidoriana (ms. Paris BN 6113). Edición crítica, traducción y estudio, Noia, Toxosoutos.

- GonZÁlez Rolán, Tomás (1981): «San Isidoro de Sevilla como fuente de Alfonso X el Sabio: un nuevo texto de las Etimologías (1. XIV) en la General Estoria (4a Parte)», Revista de Filología Española, 61-1/4, 225-234.

- ImPey, Olga Tudorica (1980): «Ovid, Alfonso X, and Juan Rodríguez del Padrón: two Castilian translations of the "Heroides" and the beginnings of Spanish sentimental prose», Bulletin of Hispanic Studies, 57, 4, 283-297.

- IMPEY, Olga Tudorica (1982): «En el crisol de la prosa literaria de Alfonso X: unas huellas de preocupación estilística en las versiones del relato de Dido», Bulletin Hispanique, 84, 5-23.

- JEREZ, Enrique (2003): «La Historia gothica del Toledano y la historiografía romance», Cahiers de linguistique et de civilisation hispaniques médiévales, 26, 223-239.

- Lida DE MalKIEL, María Rosa (1958): «La General Estoria. Notas literarias y filológicas 1», Romance Philology, 12, 2, 111-131. 
- LóPEZ SANTOS, Luis (1961): «Isidoro en la literatura medieval castellana», en Manuel C. Díaz y Díaz (ed.), Isidoriana, León, Centro de Estudios «San Isidoro» de León, 401-443.

- LoRENZo VÁzQuez, Ramón (1999): «A visión de Galicia na "Crónica Xeral Galega” e noutras "Crónicas" medievais», en Dieter Kremer (ed.), Actas do V Congreso Internacional de Estudios Galegos: Universidade de Tréveris 8-11 de outubro de 1997, vol. 2, Ediciós do Castro/Centro de Documentación de Galicia da Universidade de Trier, 575-606.

- MarTín, José Carlos (2005): «El corpus hagiográfico latino en torno a la figura de Isidoro de Sevilla en la Hispania tardoantigua y medieval (ss. VII-XIII)», Veleia, 22, 187-228.

- Menéndez Pidal, Ramón (ed.) (1906): Primera Crónica General, Estoria de España que mandó componer Alfonso el Sabio y se continuaba bajo Sancho IV en 1239, parte I: texto, Madrid, Bailly-Ballière e hijos editores.

- Millán GonZÁLEZ-PARDo, Isidoro (1971): «Nota adicional al trabajo del Profesor Juan Gil», Habis, 2, 179-182.

- Orellana, Raúl (2009): Alfonso X el Sabio General Estoria, Cuarta Parte, vol. 2, Madrid, Fundación José Antonio de Castro, en Pedro Sánchez-Prieto Borja (dir.), Alfonso X el Sabio, General Estoria, vol. 10, Madrid, Fundación José Antonio de Castro.

- Oroz Reta, José, Manuel. A. Marcos Casquero (1994): San Isidoro de Sevilla, Etimologías II, Madrid, BAC.

- Rico, Francisco (1984): Alfonso el Sabio y la General Estoria. Tres lecciones, Barcelona, Ariel.

- Rodríguez Porto, Rosa M. (2017): «The Pillars of Hercules: The Estoria de Espanna (Escorial, Y.I.2) as Universal Chronicle», en Michele Campopiano and Henry Bainton (eds.), Universal Chronicles in the High Middle Ages, York Medieval Press, 223-254.

- Rubio Álvarez, F. (1956): «Andanzas de Hércules por España, según la “General Estoria” de Alfonso el Sabio», Archivo Hispalense. Revista Histórica, Literaria y Artística, 24:75, 41-55.

- Salvo García, Irene (2012): Ovidio en la «General estoria» de Alfonso X. Tese de doutoramento. UAM.

- Sánchez-PRIETo Borja, Pedro (2009): Alfonso X el Sabio General Estoria, Primera parte, vol. 1, Madrid, Fundación Antonio de Castro.

- Sánchez-Prieto Borja, Pedro (2016): «Las maravillas del mundo en la General Estoria de Alfonso X», en Constance Carta/Sarah Finci/Dora Mancheva (eds.), Antes se agotan la mano y la pluma que su historia. Magis deficit manus et calamus 
quam eius hystoria. Homenaje a Carlos Alvar. Volumen I: Edad Media, San Millán de la Cogolla, Cilengua, 323-339.

- SeEL, Otto (1972): M. Iunianus Iustinus, Epitoma Historiarum Philippicarum Pompei Trogi, Leipzig, Teubner.

- Solalinde, Antonio G. (1934): «Fuentes de la General Estoria de Alfonso el Sabio», Revista de Filología Española, 19, 1-28.

- WeISS, Roberto (1989): La scoperta dell'Antichità classica nel Rinascimento, Padova, Editrice Antenore.

- WiKANDER, Stig (1966): «Los “Almuiuces” en la primera crónica general», Boletín de la Asociación Española de Orientalistas, 2, 109-116. 
